\title{
0 CARNAVAL NO DESFILE TRADICIONALISTA \\ UM RELATO ETNOGRÁFICO DA CONSTRUÇÃO DOS CARROS TEMÁTICOS DA SEMANA FARROUPILHA DE 2010 NOS BARRACÕES DO PORTO SECO
}

Ulisses Corrêa Duarte (UFRGS)

Investiga o processo de construção dos carros temáticos para o desfile tradicionalista gaúcho de 2010 nos barracões do Complexo Cultural Porto Seco, local dos desfiles de carnaval de Porto Alegre. Partindo dos estudos de Oliven (2006) sobre a identidade regional gaúcha, analisa a discutida relação entre o tradicionalismo e o carnaval, desenvolvendo reflexão sobre a construção da identidade das duas festas. O processo de 'espetacularização' desses eventos permite pensar um momento de atualização dessas posições identitárias, que antes pareciam binárias e inarticuláveis. A análise da forma de produção dos carros temáticos pelos trabalhadores de barracão das escolas de samba e de suas ideias e representações acerca da Semana Farroupilha informa a reflexão sobre a complementaridade e o relacionamento das duas culturas.

RIO GRANDE DO SUL, CARNAVAL, IDENTIDADES, SEMANA FARROUPILHA, "ESPETACULARIZAÇÃO", TRADICIONALISMO.

DUARTE, Ulisses Corrêa. O carnaval no desfile tradicionalista: um relato etnográfico da construção dos carros temáticos da semana farroupilha de 2010 nos barracões do Porto Seco. Textos escolhidos de cultura e arte populares, Rio de Janeiro, v.8, n.2, p. 115131, nov. 2011. 
1. O Movimento Tradicionalista Gaúcho foi criado em 1966. É a entidade associativa que congrega mais de 1.400 entidades tradicionalistas, legalmente constituídas, conhecidas por Centros de Tradições Gaúchas (CTGs) (...) É um movimento cívico, cultural e associativo. O MTG é uma sociedade civil sem fins lucrativos, dedica-se à preservação, resgate e desenvolvimento da cultura gaúcha, por entender que o tradicionalismo é um organismo social de natureza nativista, cívica, cultural, literária, artística e folclórica." (Disponivel em www.mtg. org.br/oquee.html. Disponível em setembro de 2010). Acesso em setembro de 2010)

2. Os carros temáticos são veículos sobre rodas com grandes estruturas montadas utilizando ferro, madeira, esculturas, e uma série de elementos plásticos na representação artística de uma história a ser contada, o tema, ou uma parte dele. Possuem características similares, quanto à forma dos carros alegóricos utilizados nas escolas de samba no carnaval e só se particularizam pela necessidade de representação 'realista' do tradicionalismo gaúcho, como veremos a seguir.
Pelo oitavo ano consecutivo, durante as comemorações da Semana Farroupilha do Estado do Rio Grande do Sul, em setembro, é realizado o desfile temático farroupilha. As comemorações do feriado de 20 de setembro, que marca a data de início da Revolução Farroupilha, integram a festa oficial do calendário do estado idealizada e realizada pelo Movimento Tradicionalista Gaúcho - MTG. ${ }^{1}$ Comemorada como feriado estadual regulamentado desde 1995 (Decreto Estadual 36.180/95), a Semana Farroupilha atualmente é uma das festas populares de maior repercussão no Rio Grande do Sul e recebe generoso apoio do poder público estadual e de empresas patrocinadoras através das leis do incentivo à cultura.

É promovido pelo MTG o Acampamento Farroupilha, grandiosa estrutura montada no Parque Harmonia, região central de Porto Alegre, para abrigar dezenas de Centros de Tradições Gaúchas - CTGs e suas edificações, os piquetes. O Acampamento constitui uma espécie de cidade provisória tradicionalista durante o mês de setembro para as celebrações da data até seu encerramento, no feriado do 20 de setembro. Além disso, ocorre um desfile oficial, que a partir de 2009 se desdobrou em dois, um temático, na noite de 19 de setembro, e o 'tradicional' na manhã de 20 de setembro. Uma das atrações do primeiro, e talvez a mais esperada pelo público espectador, é a exibição dos carros temáticos ${ }^{2}$ junto com os grupos tradicionalistas, que apresentam coreografias e representações de papéis das cenas típicas da vida gaúcha. $O$ tradicional, por sua vez, também chamado de desfile cívico-militar, conta com a presença da Brigada Militar, da Polícia Civil e de grupos de gaúchos a cavalo, os 'cavalarianos'.

A construção dos carros temáticos do desfile da Semana Farroupilha de 2010, assim como das oito edições anteriores, ficou a cargo de profissionais provenientes do carnaval da cidade de Porto Alegre. Dos três protagonistas da criação e elaboração dos carros temáticos de 2010, dois são carnavalescos ${ }^{3}$ e um é 'temista' das escolas de samba do primeiro grupo de competição da cidade. São eles: Mano Brum, Guarací Feijó e Sérgio Peixoto, todos com larga experiência no carnaval. Mano Brum é o pioneiro na construção dos carros temáticos farroupilhas, com participação desde a primeira edição do evento; Sérgio Peixoto desde o segundo evento, e Guarací um pouco mais tarde. Em cerca de um mês, entre agosto e setembro de 2010, foram construídos os dez carros temáticos para o desfile da véspera do feriado estadual. O local escolhido para 
a construção dos carros, pelo sétimo ano seguido, foi o Complexo Cultural do Porto Seco, ou simplesmente Porto Seco, como é referido no cotidiano.

Trata-se de uma área municipal de Porto Alegre com 15 barracões destinados à construção de carros alegóricos e uma pista de desfile de cerca de 400 metros. O projeto inicial compreendia a construção de arquibancadas fixas para a pista de desfile, com a capacidade de instalar aproximadamente 40 mil espectadores e sediar desfiles oficiais do calendário municipal e estadual, sendo os três eventos mais importantes previstos o carnaval de Porto Alegre, o desfile militar de 7 de setembro (independência do Brasil), e o desfile da Semana Farroupilha.

Com a inauguração do Porto Seco em 2004, após longa disputa judicial pela escolha do local destinado às obras, o complexo cultural saiu do papel, mas não no local idealizado pelos carnavalescos, no Centro da cidade (onde aconteciam os desfiles de carnaval desde meados do século XIX). Os barracões foram construídos no extremo norte da cidade, no bairro Rubem Berta, em local pouco urbanizado e conhecido como Porto Seco, devido à localização de muitas empresas de transporte de carga. Após longa espera por um complexo que atendesse às exigências de melhor construção de alegorias para o carnaval de Porto Alegre, os carnavalescos da cidade comemoraram, sem consenso e em meio a polêmicas, o futuro do carnaval das escolas de samba. Os desfiles dos militares e tradicionalistas no Porto Seco não saíram do papel; ambos permanecem no Centro da cidade. Dessa forma, o que era para ser um complexo cultural para os mais variados eventos da cidade transformou-se no local específico e exclusivo do carnaval porto alegrense. Assim, foi montado na cidade um espaço que centraliza as produções dos elementos plásticos das escolas de samba (em especial seus carros alegóricos) e aglutina os trabalhos para o carnaval.

Neste texto desenvolvo um estudo etnográfico de um dos dois barracões que sediaram a construção dos carros temáticos para o desfile farroupilha. Em sete oportunidades estive no

3. O termo 'carnavalesco' pode ter duas acepções: pode ser o profissional responsável por toda idealização e desenvolvimento do enredo nos elementos plásticos situados no barracão, em suma, as alegorias e fantasias (esse sentido é utilizado no carnaval do Rio de Janeiro, por exemplo). Em Porto Alegre, o carnavalesco pode significar todo indivíduo envolvido com o carnaval da cidade, em qualquer nível de inserção, desde os dirigentes aos integrantes das alas no desfile de carnaval e aos simpatizantes da festa. Utilizarei o termo no texto neste último sentido; quando no primeiro, utilizarei o termo destacando a especificidade.

4. Algumas escolas de samba da região metropolitana participam do concurso carnavalesco de Porto Alegre. É o caso do Império do Sol, que em 2010 disputou o primeiro grupo, o chamado 'Grupo Especial'. barracão gerenciado por Mano Brum, local que também é sede da Escola de Samba Império do Sol, da cidade de São Leopoldo, ${ }^{4}$ da qual ele é o carnavalesco. Responsável pela construção de três carros temáticos do 20 de setembro, Mano reúne 15 trabalhadores de barracão, exclusivamente provenientes do carnaval, para essa empreitada.

A partir da realização de meu trabalho de conclusão de curso, e atualmente na dissertação de mestrado sobre o carnaval da cidade, ${ }^{5}$ interessei-me por este novo ciclo de trabalhos que se vai afirmando a cada ano que passa com mais contratações e maior 
5. Trabalho de conclusão de curso para o título de bacharel em ciências sociais em 2009 na Universidade Federal do Rio Grande do Sul (UFRGS): "O processo de modernização numa escola de samba em Porto Alegre: 0 Império da Zona Norte e o Carnaval de 2009". Disponível na internet no site do Lume (repositório digital da UFRGS).

6. O 'mundo carnavalesco', com a assimilação da teoria de campo de Bourdieu (2010), pode ser explicado como o universo social relativamente autônomo e com regras próprias que compreende as relações entre posições sociais e capitais simbólicos dos indivíduos em disputa. destaque no universo carnavalesco: ${ }^{6}$ o desfile do 20 de setembro. A leitura de autores que constatam a particular relação da identidade regional gaúcha com os símbolos que compõem a identidade brasileira, ${ }^{7}$ além de minhas experiências em campo, que suscitam a ideia de marcante tensão e possível antagonismo entre os dois mundos, condicionou meu profundo interesse pela relação entre as duas festas. O núcleo de lideranças do MTG reforça sua posição na Semana Farroupilha pela mobilização da 'tradição' de um passado idealizado, como valor a ser cultuado. O modo como os carnavalescos e trabalhadores de barracão das escolas de samba de Porto Alegre atuam na construção do desfile temático da Semana Farroupilha e como se relacionam com os ideais do tradicionalismo gaúcho constitui as principais questões que me guiaram neste trabalho.

\section{O TRADICIONALISMO GAÚCHO VERSUS O CARNAVAL DE PORTO ALEGRE}

Inicio meu relato com a experiência etnográfica no Acampamento Farroupilha de 2005, quando acompanhei meu colega de graduação Henrique Lemes da Silva em sua pesquisa sobre o tradicionalismo. Encontramos em meio às instalações dos tradicionalistas faixas de protesto com a seguinte mensagem: "Carnaval não!" Em conversa a respeito do conteúdo do protesto, alguns tradicionalistas nos contaram a iniciativa de mo-

bilização de um grupo de CTGs no sentido de manifestar sua indignação frente à iniciativa da Secretaria Estadual da Cultura de implementar no desfile da Semana Farroupilha os carros temáticos, "que mais lembravam os carros alegóricos do carnaval". Alguns mais radicais avançavam contra o carnaval, afirmando-o incompativel com a cultura gaúcha, e sugerindo que o feriado carnavalesco fosse "anulado" no Rio Grande do Sul.

Ruben Oliven (1992), autor preocupado com a relação da identidade regional com a nacional, evidencia uma particularidade do Rio Grande do Sul em relação às demais unidades da federação. Enquanto o Estado brasileiro processa gradualmente a integração do país com a afirmação dos seus elementos culturais e a construção de identidade nacional, o estado gaúcho assiste ao renascimento da valorização de tradições e de movimentos que mobilizam sua constituição em movimento inverso. Essa reafirmação do 'gauchismo' regional se passa no momento histórico - meados do século XX - em que os intelectuais brasileiros têm por objetivo centralizar o país e homogeneizar as particularidades locais; segundo dados das agências oficiais, o Rio Grande do Sul se urbaniza e se moderniza progressivamente desde a década de 1950.

Oliven segue demonstrando que o modelo basilar na construção da identidade local é a figura idealizada do 'gaúcho', relacionada à construção de um passado que su- 
postamente existiu na região pastoril conhecida como Campanha, no sudoeste do estado. Assim, conforme o autor,

Se a construção dessa identidade tende a exaltar a figura do gaúcho em detrimento dos descendentes dos colonos alemães e italianos, ela o faz de modo mais excludente ainda em relação ao negro e ao índio que comparecem ao nível das representações de uma forma extremamente pálida (p.100).

Concordamos com a afirmação do autor de que a invisibilidade social e simbólica do negro é presente na construção identitária do tradicionalismo gaúcho, o que não compactua com as ideologias raciais brasileiras no momento da consolidação do 'mito das três raças'. Ideologia ${ }^{8}$ encontrada marcadamente em Gilberto Freyre e nos intelectuais interessados na construção da identidade brasileira, dados o valor positivo da 'mestiçagem' e os eventos que a celebram ritualmente, como o carnaval e o futebol. No Rio Grande do Sul, a identidade gaúcha se forjou com a pouca importância do negro e sua cultura, apesar de não negar sua existência e de sua condição de escravo nos séculos anteriores. Em particular, ele teve pouca relevância na reconstituição histórica clássica nos processos de guerras e revoluções, cultuados na cultura tradicionalista e na ideologia da positivação do trabalho nela presente.

Não é estranho o destaque que o negro possui nem sua predominância numérica em festas consideradas parte da cultura negra, como o carnaval. Em Porto Alegre, porção significativa de participantes dos desfiles das escolas de samba é de negros e mestiços. Essas agremiações reúnem grandes multidões e movimentam milhares de pessoas durante o ano todo, embora visando ao carnaval, que pode ser considerada a maior festa popular da cidade. Nem por isso, porém, o carnaval faz parte da vida cultural de toda a população. Ele não sensibiliza a maior parte das camadas médias que, avessas à festa, recorrentemente viajam nesse período, seja para outros estados ou internamente, seja à procura de carnavais de maior prestígio.

O tema da participação do Estado brasileiro na produção da cultura popular já foi proposto por diversos autores, que analisaram o patrocínio e o apoio de intelectuais da Primeira República (1889-1930) e na Era Vargas (1930-1945), principalmente a conversão de símbolos étnicos em nacionais. ${ }^{9}$ Alexandre Lazzari (2001), em trabalho sobre a história do carnaval de Porto Alegre na virada do século, já pontua a semelhança do modelo porto-alegrense de brincar com o carioca. Em busca de assimilação e aperfeiçoamento do modelo que foi considerado por muitos intelectuais modernistas o 'genuinamente brasi- 
leiro', os grupos carnavalescos de Porto Alegre, em vários momentos históricos, procuraram adaptar o modo de fazer carnaval da capital da República.

Procurando equiparar-se à festa carioca e ao modelo de produção de seu desfile, o carnaval porto-alegrense resulta na atualidade em incipiente 'projeto'10 de modernização do evento pelo grupo dirigente de sua principal associação. Com o complexo cultural, as escolas de samba se instalaram em barracões adequados para

10. A noção de projeto de Gilberto Velho (2006a) está associada a uma comunidade moral de valores compartilhados no nível simbólico, como no caso do 'mundo carnavalesco'. O projeto pode ser comunicado e intrinsecamente ligado à mudança social. a construção e armazenamento dos carros alegóricos, fantasias e matérias-primas, o que permitiu uma 'evolução' (na linguagem local) estética do espetáculo. Inevitavelmente, sempre em comparação e contraste com as escolas de samba cariocas. "Se parece com o Rio (de Janeiro)" é um dos qualificativos de maior prestígio e admiração que o carnavalesco de uma escola gaúcha pode receber. Essa busca de aprimoramento e constante atualização com o desfile carioca faz mais sentido ainda para o senso comum, ao se apoiar na ideia recorrente de carnaval como festa elementar nacional e "aceita passivamente, considerada uma festa que existe em todo país com poucas variações de forma e sentido" (Lazzari, p.17) - ideia, aliás, encontrada em intelectuais do movimento modernista de 1922, como Gilberto Freyre (1947) e Mário de Andrade (1983), na busca incessante de raízes nacionais valorizando o que haveria de mais "autêntico" no Brasil; e posteriormente reatualizada com novos argumentos em DaMatta (1997) e Pereira de Queiroz (1999).

A concentração da população pobre em áreas suburbanas de Porto Alegre, em regiões da cidade notavelmente de forte densidade populacional de baixo estrato social e negra na virada para o século XX, como a llhota e a Colônia Africana (já bastante transformadas e renomeadas), e junto à região de cortiços no Centro da cidade, produziu variedade bastante acentuada de formas de participar do carnaval. A mobilização pela festa passa a ser quase exclusiva das associações populares da cidade, e é massiva a participação das comunidades negras no carnaval. Essa configuração social da festa reforça a posse da 'legitimidade' cultural do carnaval nesse grupo, que passa a ser associado, pela imprensa e pelos intelectuais, ao grupo étnico possuidor "legítimo" do caráter nacional do carnaval. No desenrolar das décadas de 1940 e 1950, com o ressurgimento dos movimentos tradicionalistas e folcloristas da cultura local do estado gaúcho, assimilamse novos elementos culturais em face do projeto nacionalista associado ao carnaval. Assim, o carnaval de Porto Alegre articula-se para além da base cultural regional e espelhase nas formas que remetem à cidade do centro político-cultural do Brasil na época, o Rio de Janeiro. Atualmente em Porto Alegre existe intensa 'importação' de profissionais cariocas, que a cada ano são mais numerosos em postos que vão de intérpretes de escolas de samba, carnavalescos até coordenador-geral do carnaval - sem esquecer que a totalidade do corpo de jurados do Grupo Especial do carnaval de Porto Alegre, desde 2008, é proveniente da cidade carioca. 
De certa forma, o movimento histórico de 'periferização' do carnaval seguiu em direção ao extremo norte da cidade com a construção do complexo cultural nessa região. O que, na época, muitos carnavalescos consideraram uma derrota do carnaval, ${ }^{11}$ assim deslocado do centro do poder administrativo e político da cidade, para além da região em que foi construída a 'memória negra' e a 'memória carnavalesca'. Como Halbwachs (2006), consideramos que a memória coletiva é construída em pontos de contato entre as lembranças individuais e o grupo ao qual pertence o indivíduo. O indivíduo constrói seu sistema de valores em relação à memória compartilhada por seu grupo. $A$ memória coletiva em Halbwachs é condicionada pela dimensão espacial; ela constitui e é constituinte do sujeito no mundo. No carnaval de Porto Alegre, ao se distanciar de sua região de fundação, a memória coletiva carnavalesca é readequada em virtude do jogo de lembrança e esquecimento dos grupos em transformação; assim como a configuração social dos grupos carnavalescos em sua relação com o carnaval, abrindo novo jogo hierárquico de escolas de samba em competição, uma nova configuração política (Elias, 1994).

A ideia de que o carnaval 'se fortaleceu' nos últimos anos está ligada à ideologia da modernização de suas entidades e à 'espetacularização'12 de seu desfile. O crescimento e o fortalecimento das escolas da Zona Norte em relação às mais antigas, da área central da cidade, assimilam uma 'onda' de otimismo pelas ações e modificações do espetáculo em virtude de um novo momento do carnaval, celebrado por parte da mídia, a mesma que criticou a mudança do local dos desfiles. O fortalecimento das escolas de samba da Zona Norte (Império, Imperatriz e União da Vila do lapi), decorrente do fato de terem vencido duas das três últimas competições e obtido sempre boas colocações depois da mudança de local dos desfiles, leva a discussões mais abrangentes sobre o deslocamento do carnaval para o Complexo Cultural Porto Seco que fogem do interesse deste trabalho.

Podemos supor que o carnaval, como festa associada ao pertencimento à identidade nacional, foi mobilizado pela população negra de Porto Alegre (invisibilizada no processo de regionalização do estado gaúcho) como uma das opções na construção de sua própria identidade cultural. Ainda que os carnavalescos muitas vezes embaralhem essas posições, não estanques, não tão nítidas e nem 'puras', o carnaval de Porto Alegre assume postura política crítica
11. Como o jornalista e entusiasta do carnaval Cláudio Brito opinou, "(...) se criou um gueto para o samba, bem longe do Centro, o gueto do Porto Seco. Levamos o carnaval, que é uma festa urbana por excelência, pro mato. Lá seria um excelente lugar para fazer a Semana Farroupilha. Tem pasto e área livre à vontade. Mas os tradicionalistas continuam desfilando na Av. Augusto de Carvalho e na Av. Loureiro da Silva, pontos históricos de desfile carnavalesco. Tudo isso indica um movimento de marginalização" (revista Aplauson. 62, 2005).

12. A 'espetacularização' é um conceito atribuído para a caracterização de eventos que comportam dimensões múltiplas (Arlei, 2008), e pode ser relacionado ao formato de carnaval moderno: o público que o consome e quem o produz, ligado a uma comunidade afetiva; a transmissão de rádio e da televisão que o caracteriza como um produto cultural; a dimensão econômica (porque comporta produtos que vendem); e as regras cada vez mais racionalizáveis com o advento de novas tecnologias e de pressões por precisão na sua formatação. 
dado seu pertencimento à etnia majoritária que o constrói e o consome. E agora se atualiza no momento conjuntural brasileiro de reivindicação e luta pelos direitos e reconhecimento dos negros, de sua cultura e de sua autonomia. Assim, considero que a atual e crescente valorização da opção pela 'espetacularização' do carnaval de Porto Alegre, por parte da direção da associação que o organiza, busca equipará-lo a conquistas já consolidadas no carnaval carioca: autonomia financeira; busca de representação política dentro do estado; prestígio junto às camadas médias da cidade; e legitimidade social como "evento que se estabelece num tripé e reúne três dimensões: culturais, sociais e econô-

13. Nas palavras de José Luís Azevedo, coordenador-geral do carnaval de Porto Alegre, em conversa particular no barracão da Associação das Entidades Carnavalescas de Porto Alegre e do Rio Grande do Sul no dia 10 de setembro de 2010.

14. Acompanho Leopoldi (1978) em sua ideia de estabelecer vinculação do desempenho de atividades de uma escola de samba em escala gradual de intensidade de acontecimentos, sempre de acordo com o andamento do eixo temporal dentro do calendário anual. Estabeleço a existência de dois ciclos nos barracões do Porto Seco, o carnavalesco e o tradicionalista, o primeiro mais longo e mais intenso, e não só o ciclo carnavalesco dividido em níveis no tempo, como indica o autor. micas", e não só a festiva. ${ }^{13}$

\section{A CONSTRUÇÃO DOS CARROS: TEMÁTICOS OU ALEGÓRICOS?}

Minha inserção no barracão coordenado por Mano Brum deu-se através de meu principal interlocutor nos dois últimos ciclos carnavalescos (2009 e 2010): Estevão, escultor com trabaIhos prestados à maior parte das escolas de samba do carnaval de Porto Alegre. Junto a Estevão, dois importantes trabalhadores do barracão administrado por Mano Brum também me possibilitaram a observação e a conversação: os irmãos Alex e Eduardo (o Duda), mestres do ferro e da madeira. Reunindo as maiores qualificações no carnaval, e por isso recebendo os melhores cachês semanais, os três são profissionais da confiança de Mano Brum para a empreitada da Semana Farroupilha.

A partir do estudo comparativo, podemos estabelecer as semelhanças e diferenças nos dois ciclos de trabalhos anuais do barracão: o carnavalesco e o tradicionalista. ${ }^{14} \mathrm{O}$ ciclo que identifico como 'tradicionalista' nos barracões das escolas de samba compreende os preparativos e o processo de construção das alegorias nos meses que antecedem o desfile temático da Semana Farroupilha. Ele se localiza no calendário anual no último mês da fase 'fria' dos preparativos das escolas de samba. Normalmente no mês de outubro as de maior porte dão sua arrancada na construção de seus elementos plásticos nos barracões do Porto Seco ou aumentam progressivamente seus trabalhos para o carnaval.

Assim, a construção dos carros temáticos da Semana Farroupilha ocupa tempo estratégico do ciclo carnavalesco - o tempo da longa espera dos trabalhadores de barracão pelo início do próximo ciclo do carnaval - e abre, portanto, nova frente de trabalho para esses profissionais.

Numa estimativa aproximada dos carnavalescos dos dois barracões, cerca de 40 trabalhadores - entre escultores, serralheiros, carpinteiros, aderecistas, auxiliares de limpeza e de serviços gerais, e cozinheiras - foram contratados para a construção dos dez 
carros temáticos do desfile da Semana Farroupilha que é financiada pelos cofres públicos por intermédio da Secretaria Estadual da Cultura e das leis do incentivo à cultura. $\mathrm{O}$ estado contrata uma empresa organizadora que repassa o trabalho aos três carnavalescos. Mano Brum constrói três carros temáticos do desfile independentemente; Sérgio Peixoto e Guarací Feijó, que trabalham juntos, são responsáveis pelos outros sete.

Guarací Feijó faz todos os projetos, e seu desenho parte da compreensão e do desenvolvimento em elementos cênicos dos dez capítulos do tema do desfile, sendo cada capítulo escrito representado por um carro temático. Nesse ano o tema do desfile era: "Farroupilhas: ideais, cidadania, revolução". ${ }^{15}$ O tema é escrito pelo presidente do Instituto Gaúcho de Tradição e Folclore - IGTF, ligado à Secretaria Estadual da Cultura, o historiador e ex-presidente do MTG Manoelito Savaris. Além dessa atribuição, o IGTF faz toda a preparação, organização e desenvolvimento do desfile, e a figura central de coordenação do órgão é Alexandre Ourique, que ocupa o cargo de diretor artístico. Além de supervisionar a construção dos carros temáticos, Alexandre é responsável pela organização dos CTGs desfilantes.

A montagem dos carros temáticos do desfile tradicionalista tem muitos pontos em comum com a construção dos carros do carnaval, cuja denominação, entretanto, é diferente: 'carros alegóricos'. Segundo alguns carnavalescos, os organizadores da Semana Farroupilha preferiram o conceito de 'temático' para evitar o constrangimento de confundir o desfile com o carnaval. Além disso, os carnavalescos comumente recebem o título de 'artistas plásticos' na divulgação do desfile. Destaco uma situação interessante que me parece representar muito bem a contraposição de parte dos tradicionalistas ao carnaval:

Estevão me contou um fato inusitado. A governadora Yeda Crusius fez uma visita ao local onde estavam os carros prontos para o desfile. Conduzida por Alexandre do IGTF, ela se mostrava muito satisfeita com o resultado do trabalho das equipes dos carros temáticos. Pousou para fotos, apertou a mão de Estevão parabe-

15. Nesse ano foram apresentados os seguintes capítulos no tema de desfile: 1 . A vida em família; 2. O trabalho: lida do campo e charqueadas; 3. A religiosidade: presença do padre, o casamento $e$ o batizado; 4. As festas: o fandango, a chula, a tava e o truco; 5. Os ideais farroupilhas: assembleia provincial e as lojas maçônicas; 6. Apresentação dos líderes, com suas características; 7 . Os estrangeiros engajados na ideia republicana; 8 . A revolução: três capitais farroupilhas - Piratini, Caçapava do Sul e Alegrete; 10. Os líderes e seus destinos no pós-revolução. nizando-o pelas suas esculturas, quando um grande grupo de 'gaudérios' a cavalo estava passando ao largo, próximo à orla do Guaíba, viu que a governadora estava por lá visitando os carros. Um deles gritou com muita veemência: "por isto que ela está no meio dos 'alegóricos'. Nem gaúcha ela é!"(se referindo à naturalidade da governadora, que nasceu em São Paulo). Estevão considerou que isto seria uma reação dos gaúchos, que demonstram uma brava resistência cultural contra as coisas que não são da 'terra', contra os carros alegóricos do carnaval inseridos 'disfarçadamente' como temáticos no desfile tradicionalista (diário de campo, 19 de setembro de 2010). 
Os carros temáticos são montados em estrutura de ferro, chamada de base ou chassi, dos carros alegóricos. Normalmente as bases, de propriedade das escolas de samba, são emprestadas para o desfile da Semana Farroupilha. O empréstimo é feito mediante a doação da sobra de materiais e dos elementos montados para o desfile tradicionalista, que serão reaproveitados no carnaval. $O$ tamanho dos carros tem dimensões similares às dos carros do carnaval (de 8 a 10 metros de largura, de 12 a 20 metros de comprimento, de 10 a 12 metros de altura). A semelhança do trabalho de construção dos carros temáticos e alegóricos é grande. A maior diferença está nos elementos tradicionalistas, presentes em larga escala nos temáticos, como bois, cavalos, figuras estilizadas dos gaúchos, etc. Além do mais, forte conotação realista é a dimensão buscada na representação dos carros temáticos, enquanto no carnaval, o lúdico e o onírico seriam os aspectos mais desenvolvidos. Nas palavras de Mano Brum:

No 20 de setembro, por exemplo, tu não pode dar brilho, tu não pode usar cores muito berrantes, não pode usar cores muito fortes, tu tem que ter um segmento, um padrão até pela temática. Até porque se de repente eu começar a fazer um carro temático e botar espelho e botar muito brilho, eu termino fazendo um carnaval. E este cuidado eu tenho que ter. Por mais que o Guarací me entregue tudo mastigado, este cuidado eu tenho que ter. Eu não posso, sabe, delirar. Eu tenho que delirar, eu tenho que delirar em cima de um trabalho, mas eu sou podado. Eu tenho que saber meu limite. Já no carnaval não existe limite (entrevista em 30 de agosto de 2010).

O cuidado em não se "fazer um carnaval" nos carros temáticos é percebido pelos trabalhadores como busca do real, do verídico, dos fatos históricos, que devem ser representados com correção e realismo. Já no carnaval tem-se a 'liberdade' de criação. Os sonhos, o irrealismo, a desproporção e a imaginação podem ser utilizados com menos limitações. E eles acreditam que só a escassez de recursos materiais limita a capacidade do artista.

A ideia de que o desfile temático se espelha numa realidade do passado é fortemente compartilhada por todos os trabalhadores de barracão e pelos desfilantes dos CTGs. No dia do desfile, na concentração de uma invernada ${ }^{16}$ que representaria os cultos religiosos farroupilhas, ouvi o discurso final, anterior ao desfile, do líder desse grupo: "Isto é muito sério. Uma encenação que precisa da participa-

16. Invernadas são grupos de danças folclóricas de um CTG. ção de todos (...) não estamos fazendo algo fictício, mas algo que a gente gosta (...) viemos ser os artistas, nós não aproveitamos nada da beleza da festa. Nós somos os representados" (diário de campo, 19 de setembro de 2010).

\section{O TRADICIONALISMO NO CARNAVAL: OS TRABALHADORES DO BARRACÃO NA SEMANA FARROUPILHA}

Estevão, Alex e Duda se dizem orgulhosos de estar trabalhando para a construção dos carros do desfile tradicionalista, e todos eles acreditam na possibilidade de que de agora em diante ele se transforme num grande festival, similar aos grandes festivais fol- 
clóricos do Brasil. Estevão aposta: "daqui a alguns anos teremos um megafestival, como o de Parintins."17 Os primeiros carros temáticos, construídos em 2003, são chamados, quando comparados aos atuais, de "carrinhos de pipoca", conceito nativo largamente usado na avaliação de carros com pequenas proporções e com poucos recursos plásticos.

No ciclo farroupilha, que se prolonga ao longo de um mês, os trabalhadores em geral constatam que são mais bem pagos do que no carnaval. Além disso, a atribuição do trabalho dos carnavalescos na Semana Farroupilha é exclusivamente a construção dos carros temáticos, e Mano Brum recebe os projetos prontos para desenvolver. No carnaval, os carnavalescos têm a responsabilidade de todos os setores das escolas de samba, do desenvolvimento do tema enredo às fantasias das alas. Sabendo dessas condições, analiso com mais cautela o discurso de Mano e de Sérgio Peixoto a respeito de suas relações com tradicionalistas. Veremos adiante que os carnavalescos tratam sua relação com o tradicionalismo com absoluta 'normalidade' e, quando questionados sobre as polêmicas entre os tradicionalistas, tratam de desmitificá-las. Mano considera sua relação com os tradicionalistas "a melhor

\begin{abstract}
17. O Festival Folclórico de Parintins acontece anualmente na cidade de Parintins, no interior do Estado do Amazonas, com apresentação competitiva de dois grupos folclóricos rivais, os bois. Com 45 anos de existência, o Festival é um caso de sucesso de público, espaço na mídia televisiva, movimentação econômica e turística.
\end{abstract} possível". E quando perguntei a ele sobre a rixa que se tornou pública entre os grupos, se resumiu a comentá-la com prudência:

No começo houve uma... um... como é que vou te dizer. Uma bronca muito grande, porque eles achavam que nós íamos carnavalizar o desfile, sabe. Depois... Com o primeiro ano já foi um pouco difícil, no segundo ano foi menos difícil, e ainda no terceiro, sabe, a coisa foi amainando cada vez mais, até que se 'passou' os carros temáticos para a noite (entrevista em 30 de agosto de 2010).

Quando o questionei de forma inversa, a respeito de uma pretensa 'resistência' por parte do mundo carnavalesco ao tradicionalismo, Mano se mostrou muito mais confortável ao expor suas críticas:

Eu acho que os alguns têm essa resistência (...) E essa resistência é boba. Porque se cria, se gera trabalho para ferreiro, marceneiro, pintor, aderecista, costureira, para o comércio em geral, o turismo em geral, a rede hoteleira, para uma série de coisas. É burrice quem bota essa rivalidade em primeiro plano. Todos nós somos brasileiros, e nós estamos mexendo com a nossa história, com a nossa cultura. Então, quem tem resistência ao carnaval é burro. Quem tem resistência aos 'gauchinhos', ao 20 de setembro, é burro (entrevista em 30 de agosto de 2010).

Sérgio Peixoto acompanha a opinião de Mano sobre a relação conflituosa que existiu e se apaziguou - "Foi no primeiro e segundo ano apenas que o acirramento era mais evidente" - e complementa que agora, além de a relação ser muito boa para ambos, "existe uma importante troca". Lembrou-se do episódio das faixas no acampamento ('Carnaval Não') e ressaltou outro acontecimento bastante inusitado. Relatou ter sido vaiado por algumas "pessoas do carnaval" que das arquibancadas assistiam ao desfile 
farroupilha no primeiro ano de sua participação. Em meio às vaias ele disse ter ouvido alguns protestos indicando sua "traição" ao carnaval, fato que ele considera decorrente do boato de que ele estaria deixando essa festa.

Durante os trabalhos no barracão de Mano Brum constatei o forte sentimento de pertencimento à cultura gaúcha por parte dos trabalhadores. De acordo com o comprometimento do trabalho desses profissionais com o carnaval, se supõe que, se não todos, a maior parte se identificasse supostamente com a festa, fazendo uso das construções da identidade 'carnavalesca'. Ao longo de minhas conversas com Estevão, Alex e Duda, questionei-os em muitas ocasiões a respeito de suas visões de mundo com relação ao carnaval e ao tradicionalismo gaúcho. E o que surpreendeu foi a grande mobilização desses três trabalhadores em torno de suas noções de pertencimento à 'identidade gaúcha'. Estevão, por exemplo, se considerava "primeiro gaúcho, antes de brasileiro". Além disso, considerava o tradicionalismo "mais legítimo" na representação da cultura do Estado do Rio Grande do Sul, assinalando que o carnaval não era festa que estaria no 'sangue' dos gaúchos, compondo, assim, a interpretação - que constrói níveis de brasilidade - bastante difundida no senso comum, de que o carnaval estaria mais próximo do Brasil do Rio de Janeiro do que do Sul. Isso se desdobraria na identificação do carnaval como "cultura importada". Alex também estava de acordo com Estevão e, mais do que isso, junto com seu irmão, Duda, montou há pouco tempo um grupo voltado para a música tradicionalista gaúcha.

Alexandre, o diretor artístico do IGTF, no dia do churrasco de confraternização que marca o término dos trabalhos (no dia 17 de setembro), contou sua trajetória ligada ao tradicionalismo desde o início de sua juventude. Dizendo-se assíduo frequentador de CTGs, ele dançava nos festivais competitivos, participava ativamente das invernadas e da maior parte dos eventos ligados ao MTG. Seu pai, também tradicionalista, que o considerava muito "bitolado" para ser produtor cultural, o estimulou, entretanto, a abrir o maior 'leque [possível] de opções'. Alexandre então foi viajar, entrou em contato com o carnaval carioca, com os mais variados ritmos e culturas nordestinas, o que o fez romper o que ele considerava como "cabeça muito curta". Além disso, Alexandre tecia frequentemente duras críticas em relação ao MTG, ao excesso de conservadorismo de alguns tradicionalistas a respeito de outros ritmos e manifestações populares, como a proibição, por regulamento, da execução de ritmos não ligados ao que é considerado 'música tradicionalista' em muitos Centros de Tradição. Alexandre mostrou-se a favor de maior abertura dos CTGs aos 'ritmos brasileiros'. Quando o assunto se voltou para o 'maxixe', ${ }^{18}$ ritmo proibido pelo MTG e que recentemente alcançou relativo sucesso entre jovens no estado, instaurou-se a polêmica:

Duda, Alex e Estevão se colocaram a favor da proibição do maxixe nos CTGs, já que não se deve deixar entrar os ritmos que nada têm a ver com a 'tradição' gaúcha. Senão vai virar uma 'bagunça', na visão de todos eles. Por incrível que pareça, os trabalhadores de barracão do carnaval se identificavam com a corrente mais conservadora dos tradicionalistas. Alexandre achava uma 'bobagem' não poder tocar ritmos brasileiros, além de outras manifestações de 
outros estados (...) Estevão chegou a dizer que apoiava estes patrões de CTGs pela forte resistência da "cultura gaúcha". Ele disse: "Assim que gosto desse patrão, morre 'seco', mas não se entrega". Alexandre tentou mais uma vez demonstrar aos trabalhadores que a abertura é tão importante, que se fosse do jeito que eles consideram, não teriam os carros no desfile. Alex disse, ressaltando toda sinceridade da opinião: "por mim, não deveria ter mesmo". Depois desse embate, Alexandre desiste da argumentação que contrapunha os trabaIhadores de barracão: "eu pensei que aqui entre os carnavalescos encontraria um pensamento mais aberto" (diário de campo, 17 de setembro de 2010).

Duda considerava os desfiles das escolas de samba pouco estimulantes; por isso, o que lhe agradava, segundo ele próprio, era exclusivamente o trabalho no barracão. Encerrada essa atividade, ele preferia sair do complexo para descansar em casa, e não tinha interesse em assistir ao evento pela televisão. Alexandre, do Instituto Gaúcho de Tradição e Folclore, não só tinha interesse pelo carnaval, como era o coreógrafo responsável pela comissão de frente da Escola de Samba Acadêmicos de Gravataí, participante do primeiro grupo do carnaval de Porto Alegre.

O jogo das definições na construção de marcas de pertencimento regionais, para os trabalhadores de barracão, se dá como na construção social da identidade tradicionalista no Rio Grande do Sul. Se eles se distanciam da noção de pertencimento à cultura do carnaval, demonstra-se a definição paulatina de uma fronteira entre as categorias nativas 'ser do carnaval' e 'viver do carnaval'. Dito isso, verificamos a possibilidade de análise do que representa uma particularidade do carnaval de Porto Alegre, em especial nas diferenças regionais e étnicas que sempre mobilizam os discursos de pertencimento e de identidade dos trabalhadores de barracão em relação às duas festas analisadas. Para descortinar mais ainda o jogo de posições desses sujeitos, sem proceder, no entanto, de forma a reduzir a discussão identitária às questões étnicas, é importante destacar que todos os personagens que fazem parte deste relato são considerados brancos.

\section{O DESFILE TEMÁTICO FARROUPILHA: O CARNAVAL DOS GAÚCHOS?}

O formato do desfile farroupilha em muitos aspectos se assemelha ao do desfile de carnaval. Segundo Sérgio Peixoto, a cada ano que passa "novas ideias são propostas pelos carnavalescos para a direção do desfile", sendo que muitas delas são resultados da experiência que os profissionais trazem do carnaval. Assim, segundo Peixoto, adotou-se a ideia da criação de uma triIha sonora para tocar repetidamente no sistema de som da pista durante o desfile. Além disso, há poucos anos estimulou-se a elaboração pelos CTGs de indumentárias dos desfilantes que tivessem relação direta com os capítulos do tema do desfile. Como se pode perceber, a trilha sonora que se repete no desfi-

18. 'Maxixe' foi o nome de uma espécie de gênero musical construído a partir da apreensão de elementos da música tradicionalista gaúcha, com o suingue e a batida encontrada no pop, no axé e no pagode; e de letra simplificada com motivos mais próximos à vida na cidade. Os 'maxixeiros', como são conhecidos, montam sua linguagem visual com a utilização de indumentária gaúcha mesclada com acessórios modernos como tênis, camisa esporte, etc. 
le tradicionalista pode ser comparada com o samba-enredo, que, cantado reiteradamente, anima as escolas de samba; e a indumentária preparada pelos CTGs de acordo com o tema é comparável às fantasias das alas do carnaval.

No carnaval, o tema enredo escrito é dividido em setores, todos se articulando e contando uma parte da narrativa anual da escola. Cada setor é aberto por um carro alegórico, como no desfile tradicionalista, e nele as coreografias e a indumentária das invernadas estão relacionadas com o carro de abertura. Após cada carro temático, uma invernada apresenta coreografias e representações de papéis elaborados de acordo com os elementos desenvolvidos do tema. A dimensão competitiva fundamental no carnaval também não é dispensada no desfile tradicionalista. Apesar de não haver competição oficial com jurados e divulgação de notas, como no carnaval, os CTGs traçam uma competição extraoficial de quem faz as melhores coreografias, compõe o carro temático mais bonito, se destaca pela beleza da indumentária, etc. Mano Brum recebia visitas de líderes de CTGs no barracão, interessados em pressionar os carnavales-

\section{O Enart acontece todo} ano na cidade de Santa Cruz do Sul e envolve competições entre CTGs em 23 modalidades que compreendem: a música, a dança, a declamação, etc.

20. Canal de televisão a cabo do segmento 'comunitário', faz parte da maior rede de televisão do sul do Brasil (o grupo RBS Tevê é sucursal da Rede Globo de comunicações).

\section{Indumentária tradicio-} nalista. cos a dar atenção especial ao carro que seria composto por seu CTG. E Alexandre relatou que, numa reunião com os Centros de Tradições, teve de pedir maior colaboração entre as entidades, divididas pelo acirramento da competitividade. Em sua opinião, elas reproduziam no desfile tradicionalista a lógica de emparceiramentos e rivalidades dos CTGs existente no festival competitivo do Encontro das Artes e Tradição Gaúcha - Enart. ${ }^{19}$

A pista de desfiles fica próximo ao Acampamento Farroupilha, a cerca de 20 quilômetros do Porto Seco, no mesmo local em que os carnavalescos reivindicaram a construção do Complexo Cultural antes de 2004. Os carros temáticos são deslocados por guinchos numa grande operação que envolve fiscais de trânsito, técnicos da companhia de energia elétrica e polícia militar. Na pista são armados três lances de arquibancadas provisórias, duas tribunas reservadas para autoridades, mais uma tribuna especial para a imprensa e as emissoras de televisão. O desfile é transmitido ao vivo para todo o Rio Grande do Sul pela TV Com, ${ }^{20}$ e várias redes de televisão e jornais locais e nacionais fazem a cobertura do evento. $O$ desfile é animado pela trilha sonora oficial e anunciado por dois locutores que fazem a apresentação dos carros alegóricos e das invernadas, além de breve resumo dos temas. Sem preocupação com a evolução do desfile, como no carnaval, os carros alegóricos e as invernadas não desfilam de modo compacto, fazendo com que eventualmente se abram grandes vazios entre os grupos e os carros. Chama atenção a quantidade de grupos que investem nas apresentações coreográficas, muitas delas muito bem elaboradas.

A partir da observação empírica, pude constatar que o público do desfile é bastante heterogêneo, e não exclusivamente composto por tradicionalistas. Também podese dizer que não é muito significativo o número de pessoas com a pilcha ${ }^{21}$ tradicionalista. 
Além do mais, constata-se grande movimento de espectadores que se deslocam em automóveis particulares e transporte público, o que sugere que boa parcela do público não está instalada no Acampamento Farroupilha.

\section{CONSIDERAÇÕES FINAIS}

A partir da observação em campo e das inúmeras conversas com os trabalhadores de barracão podemos reunir algumas constatações. O carnaval de Porto Alegre vive um ciclo de renovações de seus conceitos, fazendo com que o grupo de dirigentes de sua Associação organizadora invista em ações que visam a modificações ligadas à transformação da festa popular em espetáculo. Da mesma forma, o desfile tradicionalista busca subsídios materiais e conceituais que, ligados ao IGTF e a sua empresa organizadora, e utilizando mão de obra do 'carnaval', construa um grandioso festival que, no entendimento dos envolvidos, seria futuramente comparável ao já renomado Festival Folclórico de Parintins.

Se os carnavalescos propõem adequações no desfile tradicionalista, por outro lado, o carnaval de Porto Alegre parece ter a ganhar com o desfile farroupilha. A possibilidade de os carnavalescos trabalharem duas vezes ao ano e o já anualmente previsto remanejamento das sobras de material e dos carros temáticos transmutados em alegóricos no carnaval são as principais vantagens dos carnavalescos das escolas e das próprias entidades. Peixoto e Mano lembram-se de vários casos de escolas de samba que utilizaram elementos plásticos do desfile temático e de algumas delas apresentando poucas modificações no carro construído originalmente para o cortejo tradicionalista. Em oposição, a utilização dos carros alegóricos e seus elementos nos temáticos farroupilhas é quase inexistente. Devido à proibida vinculação de elementos não ligados à temática tradicionalista bem como à preferência pelo realismo na estética dos materiais, o carnaval pouco tem a oferecer em recursos plásticos ao desfile tradicionalista. Esse quadro só será modificado quando uma renovação nos temas do desfile farroupilha acontecer, abrindo-se no sentido de mais "liberdade para se produzir a arte farroupilha", como quer Alexandre do IGTF.

Segundo Mano Brum, a ideia de que o desfile farroupilha possa estar-se carnavalizando não é correta:

são duas áreas totalmente diferentes, apesar de arte não ter subdivisões; mas são duas áreas totalmente diferentes, são dois motivos totalmente diferenciados; nós enfocamos normalmente a vida campeira, a vida gaúcha, as revoluções e trabalhamos em cima de uma realidade. O carnaval nem tem um trabaIho em cima de uma realidade (entrevista em 30 de agosto de 2010).

$\mathrm{O}$ desfile tradicionalista está fortemente articulado à noção de representação de um passado gaúcho idealizado, assim como quer o MTG. Sérgio Peixoto, porém, respondeu-me à mesma pergunta de outra forma. Em sua opinião, o 20 de setembro pode estar se 'carnavalizando' ao captar experiências já desenvolvidas nos desfiles de carnaval. 
Prefiro salientar a existência de um rigoroso movimento de 'espetacularização' dos dois eventos numa perspectiva macrossociológica, considerando que esse fenômeno está intimamente relacionado aos tempos e espaços complementares. O desfile tradicionalista do 20 de setembro no formato que se vem desenvolvendo representa reflexo de uma situação histórica antecipada pelos carnavalescos: o interesse em vincular o carnaval à formação de um produto cultural, transformando-o assim em atividade profissional, com mercado consumidor, apoio institucional e prestígio cultural junto à população da cidade. $O$ ponto fulcral e que permite esse intercâmbio de ideias e valores é a relação no espaço de convivência dos indivíduos que produzem os desfiles, a produção de sociabilidades e de intercâmbios no interior do Porto Seco.

Os barracões do carnaval permitem o avanço dessa troca, uma dinâmica de novos sentidos e representações sobre o tradicionalismo e o carnaval, e suscitam dois movimentos conjuntos: o reforço e o embaralhamento das identidades e das fronteiras que, há muito se sabe, não são tão estáticas e inarticuláveis. O Porto Seco nos mostra que há possibilidade de um novo momento para repensarmos o tradicionalismo, talvez não mais tão vinculado à redutora 'tradição', e o carnaval, talvez não mais tão ligado à resistência das classes populares e da etnia negra em Porto Alegre. As novas definições do que são e do que representam esses movimentos, em seus âmbitos particulares e em sua inter-relação podem orientar-nos para outra compreensão das construções das identidades gaúcha e brasileira. Assim como era sua proposta original, o Porto Seco, pelo menos num período do ano, deixa de ser exclusivamente uma sede do samba e passa a ser um destacado Complexo Cultural de Porto Alegre.

\section{REFERÊNCIAS BIBLIOGRÁFICAS}

ANDRADE, Mário de. O turista aprendiz. São Paulo: Duas Cidades, 1983.

BOURDIEU, Pierre. O poder simbólico. Rio de Janeiro: Bertrand Brasil, 2010.

CAVALCANTI, Maria Laura Viveiros de Castro. Carnaval carioca: dos bastidores ao desfile. Rio de Janeiro: Ed. UFRJ, 1995.

DAMATTA, Roberto. Carnavais, malandros e heróis: para uma sociologia do dilema brasileiro. Rio de Janeiro: Rocco, 1997.

DAMO, Arlei. Do dom à profissão: uma etnografia do futebol de espetáculo a partir da formação de jogadores no Brasil e na França. Tese de doutorado para o PPGAS/UFRGS, Porto Alegre, 2005.

DUMONT, Louis. O individualismo - uma perspectiva antropológica da ideologia moderna. Rio de Janeiro: Rocco, 1985.

ELIAS, Norbert. A sociedade dos indivíduos. Rio de Janeiro: Zahar, 1994.

FREYRE, Gilberto. Interpretação do Brasil. Rio de Janeiro: José Olympio, 1947.

FRÚGOLI, Heitor. Sociabilidade urbana. Rio de Janeiro: Jorge Zahar, 2007.

FRY, Peter. Feijoada e soul food, 25 anos depois. In A persistência da raça. Rio de Janeiro: Civilização Brasileira, 2005.

HALBWACHS, Maurice. A memória coletiva. São Paulo: Centauro, 2006. 
LAZZARI, Alexandre. Coisas para o povo não fazer: carnaval em Porto Alegre. Campinas: Ed. Unicamp, 2001.

LEOPOLDI, José Sávio. Escola de samba, ritual e sociedade. Petrópolis: Vozes, 1978.

OLIVEN, Ruben. A parte e o todo: a diversidade cultural no Brasil nação. Petrópolis: Vozes, 2006.

. Violência e cultura no Brasil. Petrópolis: Vozes, 1982.

ORTIZ, Renato. Cultura brasileira e identidade nacional. São Paulo: Brasiliense, 1986.

QUEIROZ, Maria Isaura Pereira de. Carnaval brasileiro: o vivido e o mito. São Paulo: Editora Brasiliense, 1999.

RODRIGUES, Ana Maria. Samba negro, espoliação branca. São Paulo: Hucitec, 1984.

SIMMEL, Georg. A natureza sociológica do conflito. In MORAES FILHO, Evaristo (org.) Georg Simmel. São Paulo: Ática, 1983.

VELHO, Gilberto. Projeto, emoção e orientação em sociedades complexas. In Individualismo e cultura: notas para uma antropologia da sociedade contemporânea. Rio de Janeiro: Zahar, 2006a.

. Subjetividade e sociedade - uma experiência de geração. Rio de Janeiro: Jorge Zahar, 2006b.

Ulisses Corrêa Duarte é mestrando do Programa de Pós-Graduação em Antropologia

Social da Universidade Federal do Rio Grande do Sul. 